\title{
Extended-focused Ultrasonography for Children with High-energy Trauma
}

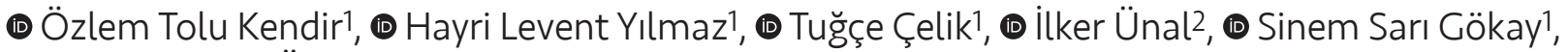 \\ (D) Ahmet Kağan Özkaya1 \\ ${ }^{1}$ Çukurova University Balcalı Hospital, Health Application and Research Center, Department of Pediatrics, Adana, Turkey \\ ${ }^{2}$ Çukurova University Balcalı Hospital, Health Application and Research Center, Department of Biostatistic, Adana, Turkey
}

\begin{abstract}
Aim: Ultrasonography (USG) is an important tool used in the diagnosis of critical patients. The present study was carried out in order to detect intra-peritoneal free liquid in cases with high-energy trauma by using "extended-focused trauma (E-FAST) USG" and to determine the diagnostic power and benefits of this method.

Materials and Methods: The medical records of pediatric cases with high-energy trauma were examined retrospectively. The results of computed tomography (CT) and radiologist-operated abdominal (Rad) USG and the demographic data of patients were compared with the results obtained from E-FAST-USG performed by a pediatric emergency specialist. Chi-square test was used to compare the categorical measurements among the groups.

Results: One hundred and sixty patients were observed during the study period. When E-FAST-USG was compared to Rad-USG, the accuracy rate of E-FAST-USG was found to be $97.5 \%$, sensitivity to be $90.9 \%$, and specificity to be $98 \%$. Forty-one of the patients were examined using CT. The sensitivity of Rad-USG was found to be $64.6 \%$ and specificity to be $93.3 \%$, whereas the sensitivity of FAST-USG was found to be $81.8 \%$ and specificity to be $93.3 \%$.
\end{abstract}

Conclusion: FAST-USG can be used in pediatric trauma cases at high sensitivity-specificity levels, and the radiation exposure of CT, which is a major consideration during childhood, can be reduced.

Keywords: Pediatric emergency, extended-focused trauma ultrasonography, high-energy trauma

\section{Introduction}

Children differ from adults in both anatomical and physiological aspects. As a result, general body trauma management includes significant differences even though the general practices are similar. Since the body mass index is low and surface/weight ratio is high among children, children may be exposed to trauma with higher levels of energy when compared to adults. For this reason, trauma may be more likely to cause multiple systemic injuries, morbidity, and mortality among children compared to adults $(1,2)$.

By using extended-focused trauma ultrasonography (E-FAST-USG), the free fluids in the pericardial and pleural spaces and the pneumothorax can be easily detected in children with high-energy trauma (2). In accordance with the Advanced Trauma Life Support Protocol, it is recommended to apply E-FAST-USG immediately after an initial examination (3).

\section{Address for Correspondence}

Özlem Tolu Kendir MD, Çukurova University Balcalı Hospital Health Application and Research Center Department of Pediatrics, Adana Turkey Phone: +903223386888 E-mail: otolu80@yahoo.com ORCID: orcid.org/0000-0002-7580-405X

Received: 22.11.2018 Accepted: 03.04.2019

${ }^{\circ}$ Copyright 2019 by Ege University Faculty of Medicine, Department of Pediatrics and Ege Children's Foundation The Journal of Pediatric Research, published by Galenos Publishing House. 
USG began to be used in emergency units in the 1990s by emergency medicine specialists who had been trained for USG, and the first guideline was published in 2001. Subsequently, articles were published between 2009 and 2012 by the Council of Emergency Medicine Residency Directors. However, there is no specific guideline in use today (4). As in our department, the use of USG has become more popular in pediatric emergency units.

During trauma management, radiography and computed tomography (CT) are more commonly used. However, since exposure to radiation during childhood may lead to later malignancy, this subject should be given importance (5). In the present study, we aimed to determine the contribution of E-FAST-USG, which is fast and reliable and has no radiation component, on treatment management.

To our knowledge, the present study is the first study on identifying the presence of intra-peritoneal free fluids (IFF), pericardial tamponade, and pneumothorax using FASTUSG by a pediatric emergency physician trained for USG in pediatric trauma patients in Turkey and on the comparison of FAST-USG with Rad-USG and CT.

\section{Materials and Methods}

In the present study, after the approval of Çukurova University Faculty of Medicine Non-interventional Clinical Research Ethics Committee (approval number: 12/59, date: 2016), the emergency records of patients admitted to the Pediatric Emergency Department of the Medical Faculty of Çukurova University between February 2015 and July 2016 were retrospectively analyzed by a single researcher. Those cases with penetrating trauma were excluded from the study. After an initial examination, the pediatric emergency specialist physician applied E-FAST-USC to the cases within the first hour, prior to radiological examination. From the files of the patients, the type of injury, vital findings, complete blood counts, biochemical laboratory results, presence of hematuria, duration of hospitalization, and surgical intervention data were collected. The results of FAST-USG, which was performed by a certified emergency pediatrician, the results of RAD USG, which was performed by a blinded radiologist and the results of abdominal CT were examined retrospectively and compared. Those cases having altered mental status, acute abdomen, undetectable bowel sounds, severe abdominal pain with sensitivity, swelling, bruising in abdomen, a decrease in hemoglobin, and those who were hemodynamically stable but were observed to have constantly increasing intraperitoneal fluid level in E-FAST imaging were taken for abdominal CT in our department (1). In the first examination, the Sonosite Edge
USG device and low-resolution convex probe (5-2 MHz), which can perform compound imaging, were used in the supine position in order to search for intraperitoneal free fluid in the hepatorenal and splenorenal regions in coronal cross-section and in perivesical areas in transverse and longitudinal cross-sections, and the cardiac examination was performed using sub-xiphoid imaging (Figure 1). Following this, by using 15-6 MHz linear probe, the presence of pneumothorax was sought in the junction of both the $2^{\text {nd }}$ and $4^{\text {th }}$ hemithoracic intercoastal space and anterior axillary line. The disappearance of pleural shifting motion and comet tail artifact lines (B lines), appearance of lung point, and barcode appearance in $\mathrm{M}$-mod (time-motion mode) imaging were considered as pneumothorax, and the results were recorded.

\section{Statistically Analysis}

The data were analyzed using the IBM SPSS Statistics 20.0 program, and chi-square test was used in comparing the categorical measurements. The statistical significance was set to $p<0.05$. Assuming that all cases had undergone CT, the Begg\&Greenes correction was performed, and the same statistical analyses were performed.

\section{Results}

A total of 160 cases were involved in the present study (102 boys and 58 girls). The mean age was $115 \pm 74$ months (median: 123 months, interquartile range $=42.25-183.25$ months).

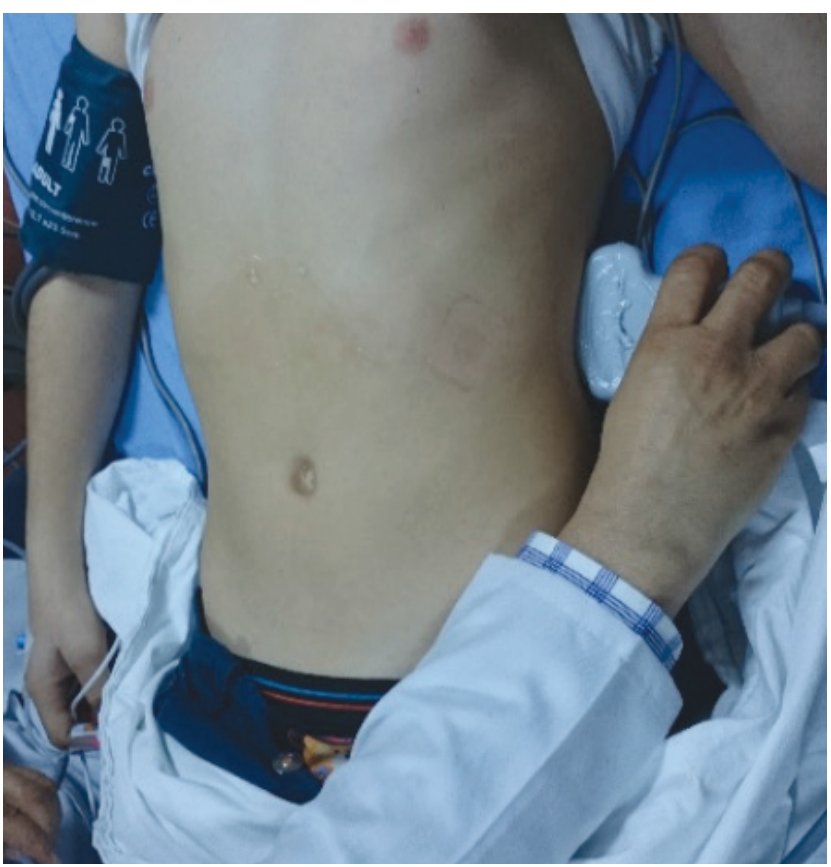

Figure 1a. A photo from an intervention in our department 
The most common reason for admission was motor vehicle accident (52.5\%), followed by falling from height (49 cases, 30.6\%) (Table I).

IFF was detected in 13 (8.1\%) patients by FAST-USG and in 11 (6.9\%) patients by Rad-USG. (Figure 2) The comparison between FAST-USG and Rad-USG is presented in Table II.

In 2 of 3 cases, in which IFF was detected using FAST-USG but not with Rad-USG, CT imaging revealed the presence of IFF. In a case in which the IFF was detected by Rad-USG, but no IFF was found by FAST-USG, CT imaging revealed no IFF.

Abdominal CT was performed for 41 patients (25.6\%) in the present study. IFF was positive in 11 (26.8\%) of them. IFF was detected by FAST-USG in 9 of these 11 patients (81.8\%) and by Rad-USG in 7 of these patients (63.6\%) (Tables Ila and III).

FAST and Rad-USG methods were found to be statistically coherent to each other (Table Ilb).

\begin{tabular}{|l|l|l|}
\hline \multicolumn{3}{|l|}{ Table I. Reasons for patients' admissions to the emergency unit } \\
\hline $\begin{array}{l}\text { Reason for admission to the } \\
\text { emergency unit }\end{array}$ & $\begin{array}{l}\text { Number of } \\
\text { patients }(\mathbf{n})\end{array}$ & $\begin{array}{l}\text { Percentage } \\
\text { (\%) }\end{array}$ \\
\hline Motor vehicle accident & 84 & 52.5 \\
\hline Falling from height & 49 & 30.6 \\
\hline Other & 27 & 16.9 \\
\hline
\end{tabular}

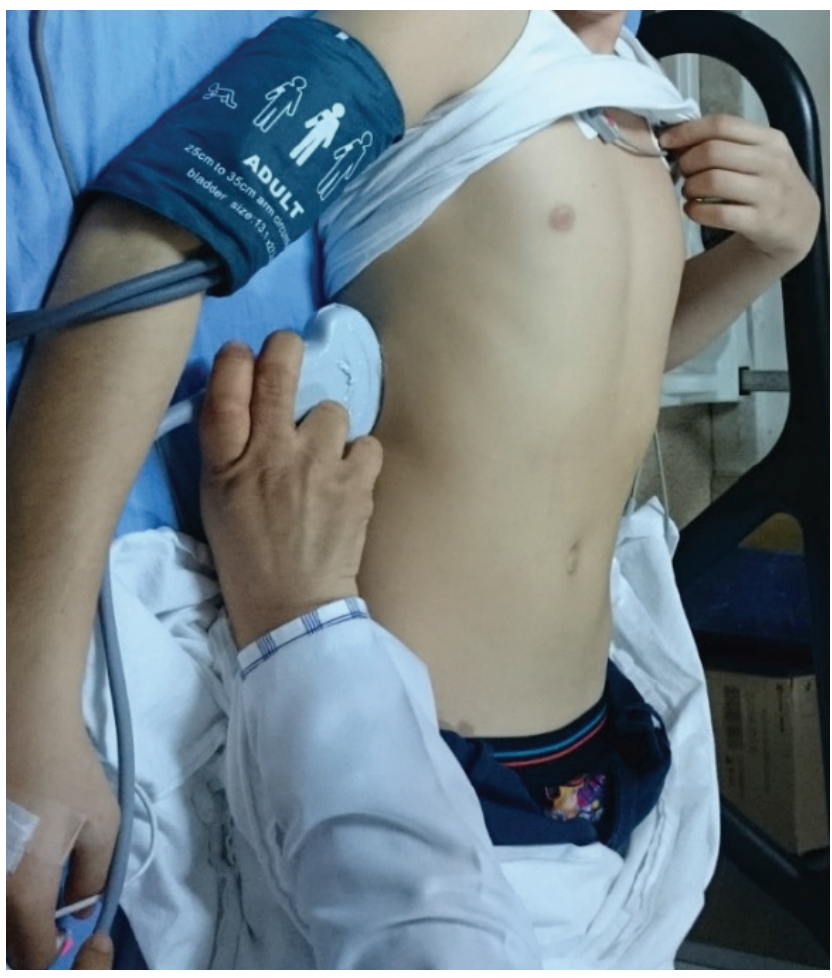

Figure 1b. A photo from an intervention in our department
In 30 cases in which no IFF was detected by CT, IFF was positive by FAST-USG for 2 cases. In one of these cases [in which IFF (+) was reported by FAST-USG, but IFF (-) by CT], minimal liver contusion was reported by $\mathrm{CT}$. In the other case, pseudo-positive free fluid was observed using RadUSG. The sensitivity of the FAST-USG method was $81.8 \%$, and the specificity was $97.3 \%$ (Table IV).

One patient's Rad-USG was IFF (+) but abdominal CT and FAST-USG were (-). In 2 of 3 cases, Rad-USG was IFF (-), but FAST-USG and abdominal CT were $(+)$.

It was assumed that all patients had undergone abdominal CT; thus, Begg\&Greenes correction was applied, and the calculations were repeated. After recalculation, it was determined that the method is highly selective (98.2\%) and more sensitive (52\%) when compared to Rad-USG (Table V).

In the first examinations of 13 patients found to have IFF by FAST-USG, 3 had hypotension, 6 had tachycardia, and 4 had tachypnea-bradypnea. In physical examinations, abdominal sensitiveness was detected in 8 patients. The hematocrit levels of 4 patients were decreased during the observation, but none of them required blood-product support.

One of 13 patients who was found to have IFF by FASTUSG died due to severe head trauma during the intensive care observation without the need for intra-peritoneal surgery. Eight patients were managed conservatively and laparotomy was performed for 4 patients. Three of those four patients underwent splenectomy, nephrectomy or bladder reconstruction procedures. Due to laceration, a drain was placed in the liver of one patient. One patient died and 4 patients who needed surgical intervention were

Table Ila. Comparison between Focused traumaultrasonography and Radiologist-operated abdominalultrasonography

\begin{tabular}{|l|l|l|l|}
\hline & $\begin{array}{l}\text { Rad-USG } \\
(+)\end{array}$ & $\begin{array}{l}\text { Rad-USG } \\
(-)\end{array}$ & Total \\
\hline FAST-USG (+) & 10 & $\mathbf{3}$ & 13 \\
\hline FAST-USG (-) & $\mathbf{1}$ & 146 & 147 \\
\hline Total & 11 & 149 & 160 \\
\hline
\end{tabular}

FAST-USG: Focused trauma-ultrasonography, Rad-USC: Radiologist-operated abdominal-ultrasonography

Table Ilb. Kappa fit index

\begin{tabular}{|l|l|l|l|}
\hline $\begin{array}{l}\text { Fit index } \\
\text { (Kappa) }\end{array}$ & Accuracy rate & Sensitivity & Selectivity \\
\hline 0.82 & $97.5 \%$ & $90.9 \%$ & $98 \%$ \\
\hline
\end{tabular}


under observation in the intensive care unit. The other seven patients in the surgery department and the other 2 patients in the emergency department unit were observed.

Additionally, in two cases, in which pneumothorax was detected by the E-FAST-USG method with disappearance of pleural shifting motion, determining the lung point and achieving the barcode appearance in M-mod examination, the pneumothorax diagnosis was supported with radiographic results but it was determined that the patients required no intervention and they recovered spontaneously (Figures 3 a-b).

\section{Discussion}

The clinical statuses of patients having blunt abdominal trauma may not be obvious at the initial examination. For this reason, repeated examination, laboratory analyses, and imaging are needed. If blunt abdominal trauma is not diagnosed or not treated sufficiently, mortality may result (5).

FAST-USG was first named by Rozycki in the early 1990s, and it began to be used routinely by emergency physicians in the initial examinations of patients (5-8). Over time, it became an integral part of advanced life support $(8,9)$. In previous studies, it was reported that the success rate of healthcare professionals in IFF imaging using the FAST method increased after having USG training (10).

As a non-invasive, affordable, and repeatable method with no radiation exposure, FAST-USC offers ease of use for the management of patients with general body trauma, but it may be disadvantageous since it depends on the experience of the operator $(6,11)$. It yields rapid and accurate results, but it may be incapable of detecting the origin of

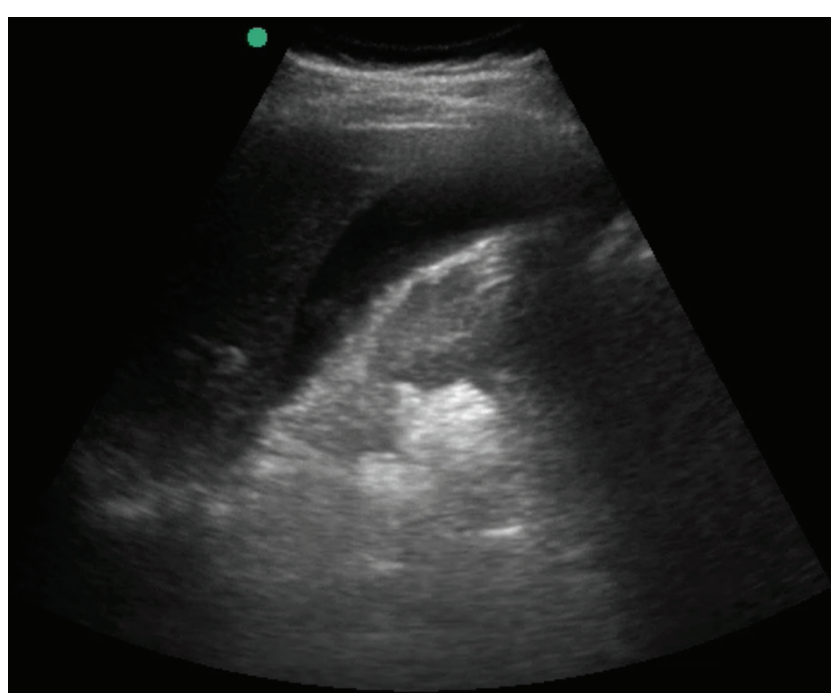

Figure 2. An image of free fluid in spleno-renal area
IFF or showing solid organ damage $(12,13)$. When compared to USC, CT depends less on the operator and it can show organ damage, but exposure to radiation is inevitable for the children (11).

In the present study, the efficiency of FAST-USG for the examination of children having general body trauma was compared with CT and Rad-USC. When compared to RadUSG, the sensitivity of FAST-USG was found to be $90.9 \%$ and its specificity to be $98 \%$ [Area Under the Curve (AUC): 97.5\%]. In line with the literature, the results of the present study indicate that this method is viable and reliable to a good degree $(8,14-17)$.

In Turkey, there have been a few studies carried out by emergency physicians on examining the reliability of the FAST-USG method. One of them was conducted by Uz et al. (9) on 107 adults, in which they determined

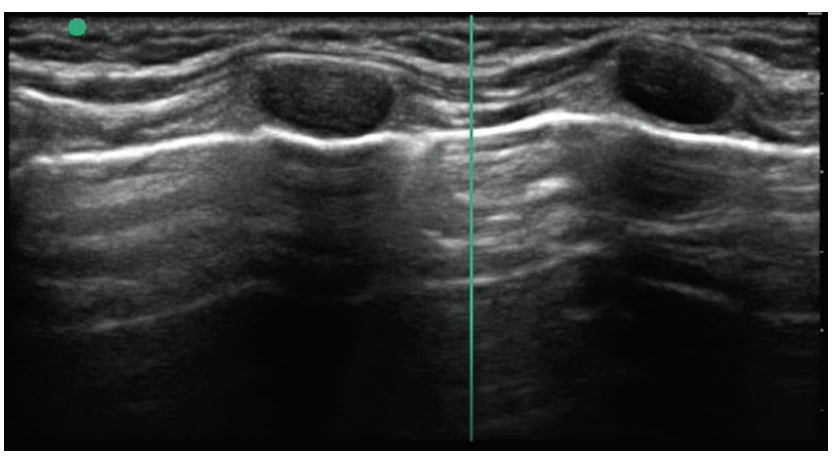

Figure 3a. A pneumothorax image from the study

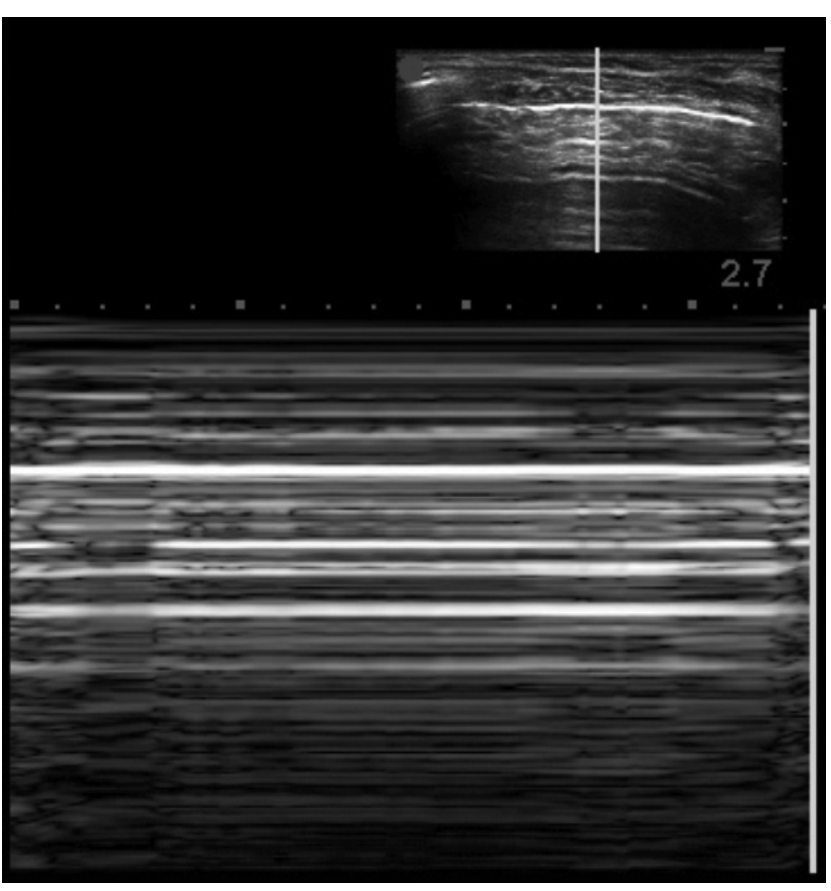

Figure 3b. A pneumothorax image from the study 
Table III. Comparison between the data of computed tomography, focused trauma-ultrasonography, and radiologist-operated abdominal-ultrasonography

\begin{tabular}{|l|l|l|l|l|l|}
\hline & BT-SS (+) & BT-SS (-) & & BT-SS (+) & BT-SS (-) \\
\hline Rad USG (+) & 7 & 2 & FAST-USG (+) & 9 & 2 \\
\hline Rad USC (-) & 4 & 28 & FAST-USG (-) & 2 & 28 \\
\hline 41 & 11 & 30 & - & 11 & 30 \\
\hline
\end{tabular}

FAST-USG: Focused trauma-ultrasonography, Rad-USG: Radiologist-operated abdominal-ultrasonography

Table IV. Reliability values of focused trauma and radiologist-operated abdominal-ultrasonography methods in comparison with computed tomography

\begin{tabular}{|l|l|l|l|l|}
\hline & Sensitivity & Selectivity & Positive-Predictive Value & Negative-Predictive Value \\
\hline Rad-USC & $63.6 \%$ & $97.3 \%$ & $63.6 \%$ & $97.3 \%$ \\
\hline FAST-USC & $81.8 \%$ & $97.3 \%$ & $69.2 \%$ & $98.6 \%$ \\
\hline
\end{tabular}

Rad-USG: Radiologist-operated abdominal-ultrasonography, FAST-USG: Focused trauma-ultrasonography

Table V. Comparison of radiologist-operated abdominalultrasonography and focused trauma-ultrasonography with the computed tomography method after Begg\&Greenes correction

\begin{tabular}{|l|l|l|}
\hline & Sensitivity & Selectivity \\
\hline Rad-USG & $31.5 \%$ & $98.2 \%$ \\
\hline FAST-USC & $52 \%$ & $98.2 \%$ \\
\hline
\end{tabular}

Rad-USG: Radiologist-operated abdominal-ultrasonography, FAST-USG: Focused trauma-ultrasonography

intra-abdominal injury and hemothorax by the E-FASTUSC method compared to the gold standard method of CT. Also, Uz et al. (9) reported the sensitivity levels of the methods to be $54.5 \%$ and $71 \%$, respectively, and no surgical intervention was necessary for those patients who had IFF but the E-FAST method did not revealed the presence of IFF. In the same study, Uz et al. (9) determined that the E-FAST-USG method identified pneumothorax with $81.8 \%$ sensitivity and $100 \%$ specificity. To the best of our knowledge, the present study is the first one that has been carried out by pediatric emergency physicians in Turkey.

lanniella et al. (18) carried out a study on 368 patients with unstable hemodynamics by CT examination as a reference; they reported that the E-FAST method had $80 \%$ sensitivity and $99.8 \%$ specificity (AUC: 97.2). Among our patients, two patients were diagnosed with pneumothorax using both X-ray and E-FAST-USG methods, and no CT imaging was applied to these patients during the observation period. No surgical intervention was required during observation.

In the literature, the sensitivity and specificity of the FAST-USG and Rad-USG methods were reported to be 52\%-
$100 \%$ and $96 \%-99 \%$ respectively (8,14-16). Zamani et al. (8) compared the Rad-USG and FAST-USG methods for 138 patients aged between 4 and 65 years and they reported the sensitivity and specificity of FAST-USG to be $84.6 \%$ and $97.6 \%$, respectively.

Menaker et al. (19) emphasized that FAST-USG might reduce the use of abdominal $C T$ in cases in which the physicians are suspicious of low- and mild-level intraabdominal injury.

Of the 160 patients whose files we examined, 41 had undergone abdominal CT. Eleven patients had IFF. The presence of fluid was detected using FAST-USG in 9 of these patients. In CT examinations of the remaining two patients, free fluid was found in the hepatorenal area of one patient, and hematoma was detected in the presacral area of the other patient. Since there was no indication due to other clinical or laboratory findings, the other patients were not taken for $\mathrm{CT}$ imaging. Our patients were observed using repeated physical examination, laboratory analyses, FAST, and Rad-USG methods. The FAST-USC method, which is believed to be reliable to a good degree based on the results of the present study, may significantly contribute to the observation of pediatric patients with trauma in emergency departments and it may also limit radiation exposure by reducing the need for CT imaging.

Similar to the present study, Faruque et al. (17) also reported in their study, in which they confirmed the images of 31 cases by using CT imaging and they applied FAST-USC to 174 patients aged between 0 and 14 years, the sensitivity of the method was $91 \%$ and the specificity level was $95 \%$. In a study by Schleder et al. (20), in which the authors 
accepted CT as the gold standard, they detected IFF in 31 patients using FAST-USC and reported the sensitivity to be $75 \%$ and specificity to be $100 \%$.

FAST-USG can be used as the initial examination and scanning test, and it may enable observation without CT examination for patients with stable hemodynamics (21). In the literature, there are few studies on the observation of pediatric patients with stable hemodynamics using only a repeated FAST-USG method $(17,22)$. In the present study, in which the CT method was applied to 41 patients because of clinical suspicion or blunt abdominal trauma, 119 patients were observed using repeated USG in addition to clinical observation. In the literature, it is emphasized that unstable patients with blunt abdominal trauma should be taken to the operating room, and stable patients can be observed using repeated USG until there is a clinical change $(17,23,24)$. Boutros et al. (25) studied 120 patients aged between 1 and 45 years and took the CT as reference and reported the sensitivity and specificity to be $93 \%$ and $99 \%$ for FAST-USG. In addition, they reported that three patients with unstable hemodynamics were directly taken to the operating room. On the other hand, it is also stated in literature that CT imaging might be necessary since USG might be insufficient in those patients in whom retroperitoneal injury is suspected (26).

Natarajan et al. (11), in their study carried out on 2.105 patients, 88 of whom had positive findings and taking diagnostic peritoneal lavage and CT as reference, showed that, different from the literature and the present study, FAST-USG is not sensitive, but selective to a good degree similar to the present study (sensitivity: 43\%, specificity: 99\%).

\section{Study Limitations}

The present study has certain limitations such as being carried out retrospectively and not all patients having undergone CT imaging.

\section{Conclusion}

USG is an easy-to-apply and non-invasive bedside method that can be used as a scanning test for pediatric patients with trauma. Since surgical intervention is not always necessary for those patients with IFF, repeated USC imaging may be required. Thus, the patient can be observed while limiting radiation exposure. At the same time, it may also enable a child with unstable hemodynamics to be taken immediately to the operating room after a positive FAST-USG.

\section{Ethics}

Ethics Committee Approval: Approved by Çukurova University Faculty of Medicine Non-interventional Clinical Research Ethics Committee (approval number: 12/59, date: 2016).

Informed Consent: Retrospective study.

Peer-review: Externally peer-reviewed.

\section{Authorship Contributions}

Surgical and Medical Practices: Ö.T.K., H.L.Y., T.Ç., S.S.G., A.K.Ö., Concept: Ö.T.K., Design: Ö.T.K., Data Collection or Processing:Ö.T.K., H.L.Y., T.Ç., S.S.G., A.K.Ö., Analysis or Interpretation: Ö.T.K., I.Ü., Literature Search: Ö.T.K., Writing: Ö.T.K., H.L.Y.

Conflict of Interest: The authors have no conflicts of interest relevant to this article to disclose.

Financial Disclosure: The authors have no financial relationships relevant to this article to disclose.

\section{References}

1. Günaydın M. Çocuklarda Travma. Yucel O, editors. Pratik Acil Tıp Cep Kitabı, Çocuklarda Travma. Derman Tıbbi Yayıncılık; 2015. p.54-107

2. Menaker I, Blumberg S, Wisner DH, et al. Use of the focused assessment with sonography for trauma (FAST) examination and its impact on abdominal computed tomography use in hemodynamically stable children with blunt torso trauma. I Trauma Acute Care Surg 2014;77:427-32.

3. American collage of surgeons' committee on Trauma; International ATLS working group. Advanced travma life support: the ninth edition. I Trauma Acute Care Surg; 2013. p.1366.

4. Marin JR, Lewiss RE. Point-of-Care ultrasonography by pediatric emergency medicine physicians. Pediatrics 2015;135:1113-22.

5. Shah J, Shah J, Modi J, Jain N. Evaluation of focused abdominal sonography for trauma (Fast) in blunt abdominal trauma (Bat). GJRA 2015;4:238-40.

6. Bailey and Love's Short Practice of Surgery. Williams NS, Bulstrode CJK, O'connell PR, editors. 25th edition. Hodder Arnold, 2008.p.1536.

7. Gallagher RA, Levy JA. Advances in point-of-care ultrasound in pediatrice mergency medicine. Curr Opin Pediatr 2014;26:265-71.

8. Zamani M, Masoumi B, Esmailian M, Habibi A, Khazaei M, Esfahani MM. A comparative analysis of diagnostic accuracy of focused assesment with sonography for trauma performed by emergency medicine and radiology residents. Iran Red Crescent Med / 2015;17:e20302

9. Uz I, Yürüktümen A, Boydak B, et al. Acil serviste "Genişletilmiş Acil Travma Ultrasonografisi" uygulamalarının klinik karar üzerine etkisi. Ulus Travma Acil Cerrahi Derg 2013;19:327-32.

10. Crouch AK, Dawson M, Long D, Allred A, Madsen T. Perceived confidence in the FAST exam before and after an educational intervention in a developing country. Int J Emerg Med 2010;3:49-52. 
11. Natarajan B, Gupta PK, Cemaj S, Sorensen M, Hatzoudis GI, Forse RA. FAST scan: Is it worth doing in hemodynamically stable blunt trauma patients? I surg 2010;148:695-700.

12. Gallgher R, Vieria R, Levy J. Bedside ultrasonography in the pediatric emergency department the focused assessment with sonography in trauma examination uncovers an occult intraabdominal tumor. Pediatr Emer Care 2012;28:1107-11.

13. Wiliams SR, Perera P, Gharahbaghian L. The FAST and E-FAST in 2013: Trauma Ultrasonography overview, practical techniques, controversies, and new frontiers. Crit Care Clin 2014;30:119-50.

14. Brooks A, Davies B, Smethhurst M, Connolly J. Prospective evaluation of non-radiologist performed emergency abdominal ultrasound for haemoperitoneum. Emerg Med / 2004;21:580-1.

15. Ingeman JE, Plewa MC, Okasinski RE, King RW, Knotts FB. Emergency physician use of ultrasonography in blunt abdominal trauma. Acad Emerg Med 1996;3:931-7.

16. Fox IC, Boysen M, Charahbaghian L, et al. Test characteristics of focused assessment of sonography for trauma for clinically signifcant abdominal free fluid in pediatric blunt abdominal trauma. Acad Emerg Med 2011;18:477-82.

17. Faruque AV, Qazi SH, Khan MAM, Akhtar W, Majeed A. Focused abdominal sonography for trauma (FAST) in blunt paediatric abdominal trauma. J Pak Med Assoc 2013;63:361-4.

18. Ianniella S, Giacomo VD, Sessa B, Miele V. First-line sonographic diagnosis of pneumothorax in major trauma:accuracy of e-FAST and comparison with multidetector computed tomography. Radiol Med 2014;119:674-80.

19. Menaker J, Blumberg S, Wisner DH, et al. Use of the focused assessment with sonography for trauma (FAST) examination and its impact on abdominal computed tomography use in hemodynamically stable children with blunt torso trauma. I Trauma Acute Care Surg 2014;77:427-32.

20. Schleder S, Dendl LM, Ernstberger A, et al. Diagnostic value of a hand-carried ultrasound device for free intra-abdominal fluid and organ lacerations n majör trauma patients. Emerg Med I 2013;30:e20

21. Cagini L, Gravante S, Malaspina CM, et al. Contrast enhanced ultrasound (CEUS) in blunt abdominal trauma. Critical Ultrasound Journal 2013;5:S9.

22. Blackbourne LH, Soffer $D$, McKenney $M$, et al. Secondary ultrasound examination increases the sensitivity of the FAST exam in blunt trauma. J Trauma 2004;57:934-8.

23. Branney SW, Moore EE, Countrill SV, Burch JM, Terry SJ. Ultrasound based key clinical pathway reduces the use of hospital resources for the evaluation of blunt abdominal trauma. I Trauma 1997;42:1086-90.

24. Ballard RB, Rozycki GS, Newman PG, et al. An algorithm to reduce the incidence of falsenegative FAST examinations in patients at high risk for occult injury. I Am Coll Surg 1999;189:14551.

25. Boutros SM, Nassef MA, Abdel-Ghany AF. Blunt abdominal trauma: The rol of focused sonography in assessment of organ injury and reducing the need for CT. Alexandria journal of Medicine 2016;52:35-41.

26. Prasad GV, Sarvottam A, Singh R. Comparative study of ultrasound and computed tomografi in the evaluation of abdominal trauma. I of Evidence Based Med and Hlthcare 2015;2:7151-61. 